\title{
Late Occurrence of Sphenoid Pyocele after Pituitary Surgery
}

\author{
George Kovoor $^{1} \quad$ Kamble J. Harsha $^{2} \quad$ Akash K. George ${ }^{3} \quad$ Venkat R. Reddy ${ }^{1}$ \\ ${ }^{1}$ Department of Neurosurgery, Brain and Spine Centre, Indo- \\ American Hospital, Vaikom, Kottayam, Kerala, India \\ ${ }^{2}$ Division of Neuroradiology, Brain and Spine Centre, Indo-American \\ Hospital, Vaikom, Kottayam, Kerala, India \\ ${ }^{3}$ Department of Research and Development, Brain and Spine Centre, \\ Indo-American Hospital, Vaikom, Kottayam, Kerala, India \\ Indian J Neurosurg 2017;6:44-46. \\ Address for correspondence Dr. George Kovoor, MS, MCh, \\ Department of Neurosurgery, Indo-American Hospital, Brain and Spine \\ Centre, Vaikom, Kerala 686143, India \\ (e-mail: drkovoor@gmail.com; drkovoor@me.com).
}
Abstract
Keywords
- pituitary
- transsphenoidal
- adenoma
- pyocele
- endonasal

The transsphenoidal approach to lesions of the sella turcica, especially for pituitary tumors, has been favored by neurosurgeons because of decreased perioperative patient morbidity and mortality of this approach compared with others. It is widely accepted because of its minimally invasive and maximally effective procedure. We report a rare case of a 63-year-old female patient with the asymptomatic delayed occurrence of sphenoid pyocele, 6 years after the initial pituitary surgery, and remained asymptomatic during this long interval.

\section{Introduction}

The endoscopic endonasal transsphenoidal approach to lesions of the sella turcica, especially for pituitary tumors, has been preferred by neurosurgeons because of reduced perioperative patient morbidity and mortality. In recent years, especially after the introduction of new tools such as endoscope and magnetic resonance imaging, transsphenoidal surgery (TSS) has become a safe technique with a low complication rate and this approach is widely accepted because of its minimally invasive and maximally effective procedure. Here, we report a rare case of pituitary macroadenoma recurrence with sphenoid pyocele 6 years after TSS-related postoperative complications.

\section{Case Report}

A 63-year-old female patient was admitted to a private hospital in 2005 with insidious onset and progressive visual loss on the lateral aspect of both eyes, left more than right. Initial brain magnetic resonance imaging (-Fig. 1A, B) showed sellar enhancing lesion extending into suprasellar region, causing compression and superior displacement of the optic chiasm. The left internal carotid artery was encased while right cavernous sinus was normal; inferiorly the mass was limited to the sphenoid sinus. Imaging features were suggestive of pituitary macroadenoma. She underwent surgical excision, histopathology confirmed as pituitary macroadenoma. During the postoperative period she had cerebrospinal fluid rhinorrhea and signs of meningitis.

After 5 year asymptomatic postsurgery period, in 2011 she presented to our institute with complaints of gradually progressive visual loss of 1 year duration, but she did not reveal any evidence of acute intracranial infection/meningitis and was afebrile. Magnetic resonance imaging revealed recurrence of pituitary macroadenoma with fluid intensity collection within the sphenoid sinus (-Fig. 2A, B). During endoscopic TSS, pyocele ( - Fig. $\mathbf{3}$ ) was initially drained from the sphenoid sinus followed by macroadenoma excision. The postoperative magnetic resonance image showed significant reduction in sellar tumor, near total evacuation of sphenoid sinus pyocele ( - Fig. 4 ).

\section{Discussion}

Sinuses have been used as a corridor to access the pituitary fossa for over 100 years. In the late 1970s, received

April 8, 2015

accepted

January 18, 2016

published online

July 14,2016

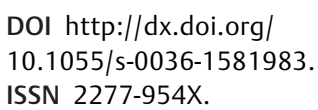

(c) 2017 Neurological Surgeons' Society
of India

License terms

(ब)(1) $\Theta$ 


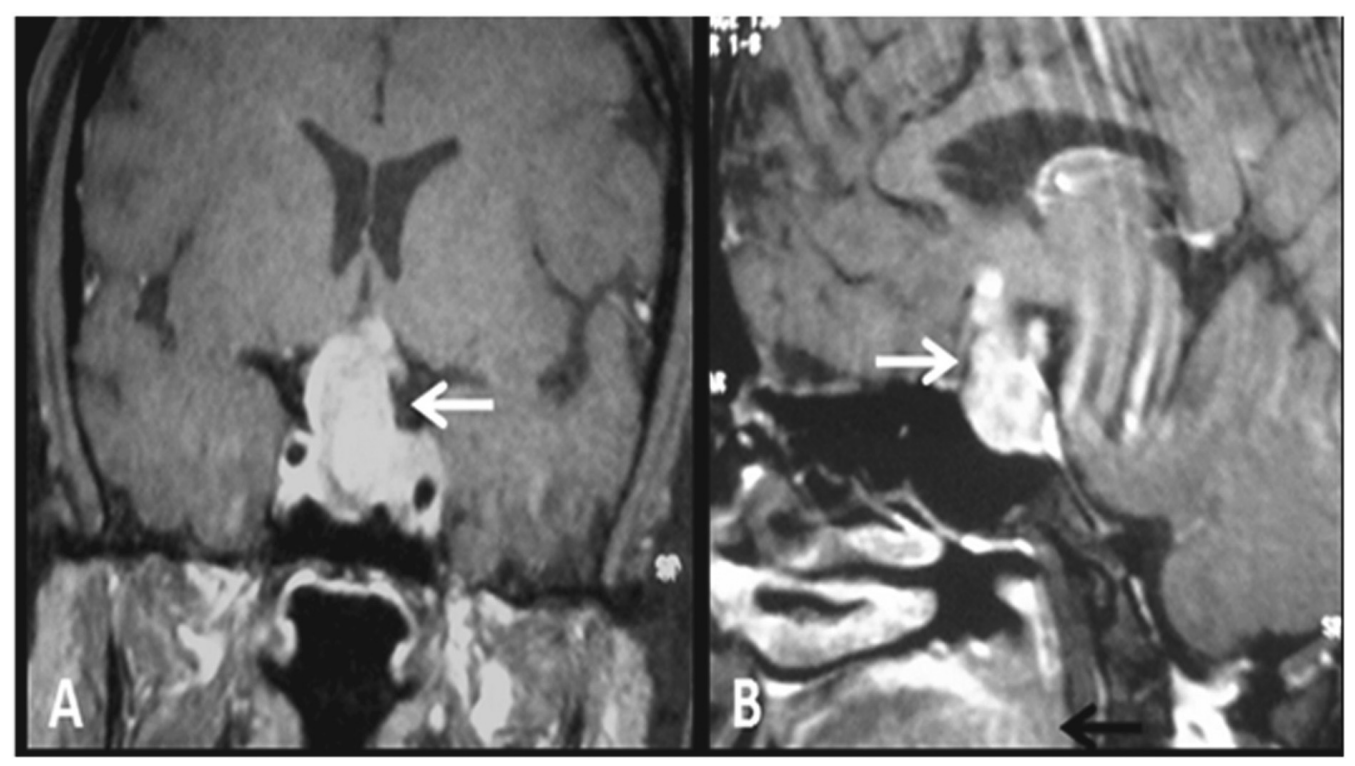

Fig. 1 Initial preoperative contrast enhanced coronal (A) and sagittal (B) T1-weighted magnetic resonance images showing lobulated homogenously enhancing sellar lesion with suprasellar extension (arrows) and compression of the optic chiasma.

Apuzzo et al $^{1}$ as well as Halves and Bushe ${ }^{2}$ demonstrated the use of endoscope as an adjunctive tool to remove pituitary lesions. The endoscope-guided TSS was standardized in actual clinical practice by Jho and Carrau $^{3}$ and Cappabianca et al. $^{4}$ In following years, endoscopic surgery became accepted widely as a safe technique with a low complication rate. ${ }^{5}$ The common complications involving the intracranial compartment are anterior pituitary insufficiency, leakage of cerebrospinal fluid from the brain, problems with fluid balance such as diabetes insipidus and meningitis. ${ }^{6,7}$ The possible extracranial complications are epistaxis or sinusitis in the early postoperative period. The formation of a sphenoid sinus mucocele is a late complication occurring with a time interval of 12 to 17 years after the surgery. ${ }^{8}$ The risk factors for the development of mucocele are scar tissue formation and limited opening of the sphenoid sinus. ${ }^{9}$ If the contents of a mucocele become secondarily

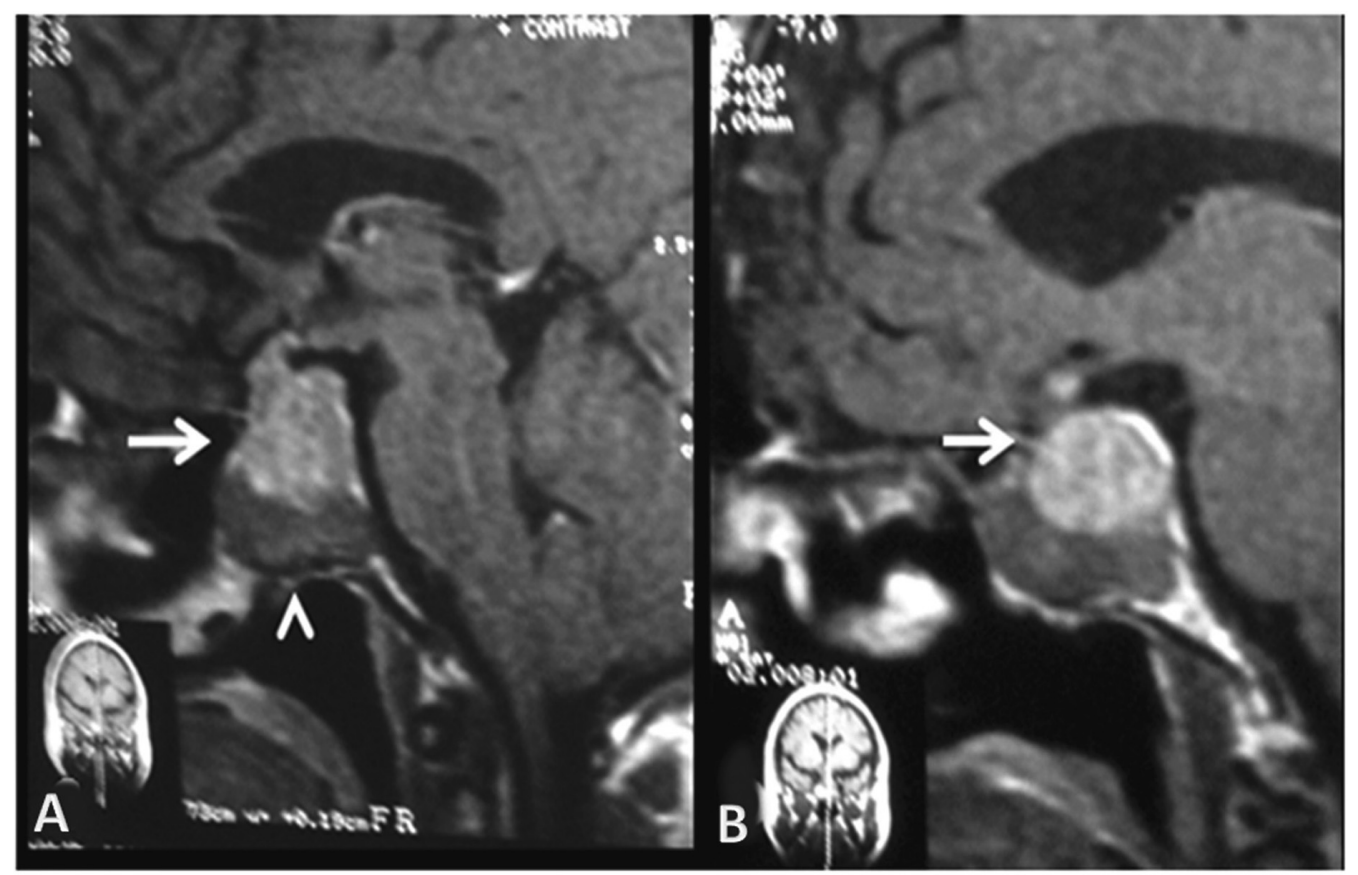

Fig. 2 T1-weighted postcontrast sagittal images (A and B) show recurrent homogenously enhancing sellar lesion with suprasellar extension (arrow) and compression of optic chiasma. No abnormal contrast enhancement noted around the sphenoid sinus collection (arrowhead). 


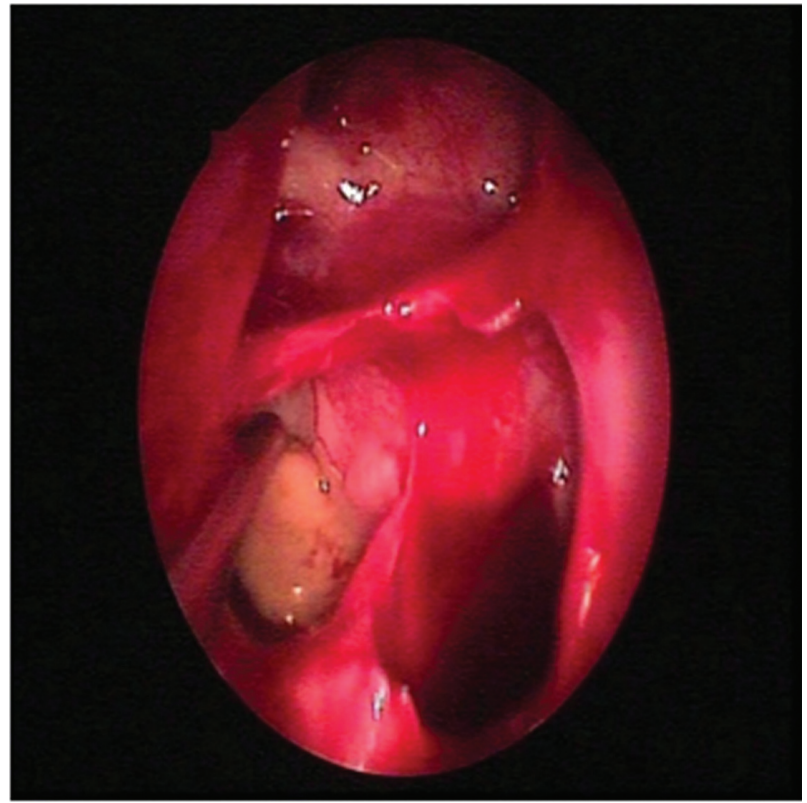

Fig. 3 Intraoperative endoscopic image showing thick yellow colored pus inside the sphenoid sinus.

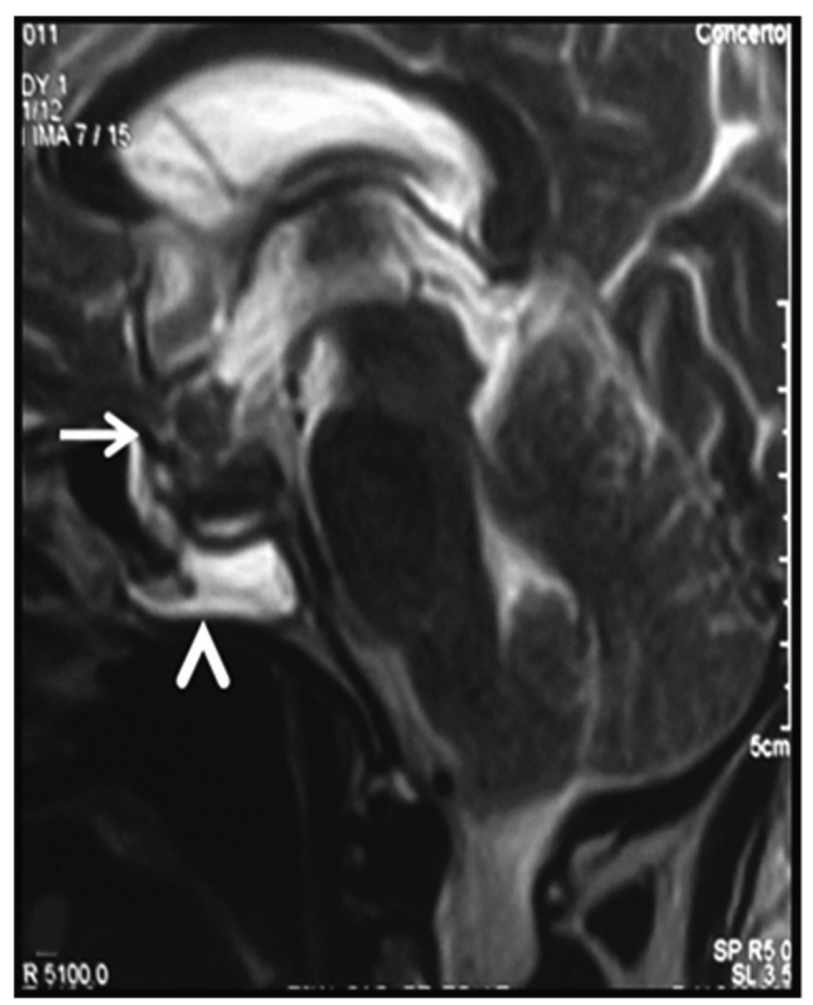

Fig. 4 Postoperative image showing T2-weighted midsagittal section showing significant reduction in sellar tumor, near total evacuation of the sphenoid sinus pyocele. infected, that can transform it into a pyocele. Development of asymptomatic sphenoid pyocele 6 years after the first TSS is very rare. Early surgical intervention is highly recommended in such cases. Also, endoscopic drainage with wide opening of the sphenoid sinus and marsupialization $^{10}$ is a treatment of choice to avoid recurrences. Delayed diagnosis and treatment leads to several severe complications. This report emphasizes the importance of further care and long-term follow-up after TSS, especially those who have a history of postoperative complications. This will help to improve the outcome of the less invasive surgical technique and patient satisfaction.

\section{Conflict of Interest \\ None.}

\section{Funding}

None.

\section{References}

1 Apuzzo ML, Heifetz MD, Weiss MH, Kurze T. Neurosurgical endoscopy using the side-viewing telescope. J Neurosurg 1977; 46(3):398-400

2 Halves E, Bushe KA. Transsphenoidal operation on craniopharyngiomas with extrasellar extensions. The advantage of the operating endoscope [proceedings]. Acta Neurochir Suppl (Wien) 1979;28(2):362

3 Jho HD, Carrau RL. Endoscopic endonasal transsphenoidal surgery: experience with 50 patients. J Neurosurg 1997;87(1): 44-51

4 Cappabianca P, Cavallo LM, Colao A, et al. Endoscopic endonasal transsphenoidal approach: outcome analysis of 100 consecutive procedures. Minim Invasive Neurosurg 2002;45(4):193-200

5 Kanter AS, Dumont AS, Asthagiri AR, Oskouian RJ, Jane JA Jr, Laws ER Jr. The transsphenoidal approach. A historical perspective. Neurosurg Focus 2005;18(4):e6

6 Buchfelder M, Fahlbusch R. Complications of transsphenoidal surgery. In: Landolt AU ed. Pituitary Tumors. Wien, Austria: Springer- Verlag; 1996

7 Ciric I, Ragin A, Baumgartner C, Pierce D. Complications of transsphenoidal surgery: results of a national survey, review of the literature, and personal experience. Neurosurgery 1997; 40(2):225-236, discussion 236-237

8 Buchinsky FJ, Gennarelli TA, Strome SE, Deschler DG, Hayden RE. Sphenoid sinus mucocele: a rare complication of transsphenoidal hypophysectomy. Ear Nose Throat J 2001;80(12):886-888

9 Lu YJ, Chang CN, Pai PC, Wei KC, Chuang CC. Isolated sphenoid sinusitis or mucocele: a potential complication of endonasal transsphenoidal surgery. J Neurooncol 2009;91(1):63-67

10 Weber R. Endonasal frontal sinus surgery. Part 1: Frontal sinus drainage, types I and II [in German]. HNO 2009;57(8):739-750 